\title{
Patogenia da doença pulmonar obstrutiva crônica
}

\author{
The pathogenesis of chronic obstructive pulmonary disease
}

Rogério Rufino*

Cláudia Henrique da Costa

\section{Resumo}

A doença pulmonar obstrutiva crônica (DPOC) é uma condição lentamente progressiva, caracterizada por limitação do fluxo de ar, que é em grande parte irreversível. O tabagismo é o principal fator etiológico. Portanto, a patogênese da DPOC está fortemente relacionada aos efeitos do fumo do cigarro nos pulmões. A história de tabagismo e a gravidade da limitação do fluxo de ar geralmente são relacionadas, mas com grande variação individual. A patogênese da DPOC engloba uma série de processos lesivos, que incluem a resposta inflamatória anormal dos pulmões a partículas inaladas e gases. Outros processos, tais como a resolução deficiente da inflamação, a falha na reparação de células anormais, a apoptose precoce, a destruição da matriz extracelular pelo desequilíbrio protease/antiprotease e oxidante/antioxidante são mecanismos patogênicos envolvidos na doença. As respostas inflamatórias crônicas subsequentes levam a hipersecreção de muco, remodelação das vias aéreas e destruição alveo- lar. Este artigo fornece uma atualização sobre os mecanismos celulares e moleculares destes processos na patogênese. A DPOC é uma doença inflamatória com participação ativa de macrófagos, neutrófilos e linfócitos CD8, associados ao estímulo de oxidante que ferem diretamente a estrutura do pulmão. Estas reações bioquímicas desenvolvem progressivamente alterações nas pequenas vias aéreas e levam um novo modelo de irreversibilidade da estrutura pulmonar. Substâncias libertadas pelas células recrutadas e pelo estresse oxidante trazem desequilíbrio temporário de mecanismos de defesa pulmonar. Desequilíbrio que por longo tempo é uma das ferramentas à fisiopatologia até a data. Os autores descrevem a relação entre estrutura, células e bioquímica na DPOC e suas consequências fisiopatológicas.

Descritores: Doença pulmonar obstrutiva crônica; Etiologia; Inflamação. 


\section{Abstract}

Chronic obstructive pulmonary disease (COPD) is a slowly progressive condition characterized by airflow limitation, which is largely irreversible. Cigarette smoking is the main etiologic factor in this condition, far outweighing any other risk factors. The pathogenesis of COPD therefore is strongly linked to the effects of cigarette smoke on the lungs. The extent of smoking history and the severity of airflow limitation are generally related, but with huge individual variation. The pathogenesis of COPD encompasses a number of injurious processes, including an abnormal inflammatory response in the lungs to inhaled particles and gases. Other processes, such as failure to resolve inflammation, abnormal cell repair, apoptosis, abnormal cellular maintenance programs, extracellular matrix destruction (protease/antiprotease imbalance), and oxidative stress (oxidant/antioxidant imbalance) have also a role. The subsequent chronic inflammatory responses lead to mucus hypersecretion, airway remodeling, and alveolar destruction. This article provides an update on the cellular and molecular mechanisms of these processes in the pathogenesis. COPD is an inflammatory disease with active participation of macrophages, neutrophils, and CD8 lymphocytes, associated to oxidant stimulus which directly injures lung structure. These biochemistry reactions progressively develop alterations in small airways and take a new model of non-reversible pulmonary structural. Substances liberated by recruited cells and by oxidants stress brought temporary imbalance of pulmonary defense mechanism. This long time imbalance is one of the tools to up to date pathophysiology. The authors describe the relationship among structure, cells and biochemistry in COPD and its patho-physiological consequences.

Keywords: Pulmonary disease, chronic obstructive; Etiology; Inflammation.

\section{Histórico da DPOC}

Laennec foi pioneiro quando descreveu o enfisema pulmonar nas necropsias de pulmões humanos. ${ }^{1}$ Ele atribuiu as lesões identificadas como decorrentes da atrofia pulmonar. Isto resultaria em uma "hiperinsuflação pulmonar compensatória”. Até o final da década de 50, esta foi a teoria mais considerada. ${ }^{2}$ Os conceitos foram novamente revistos no Simpósio da Ciba, em 1959, que definiram o enfisema como "uma dilatação distal, anormal e permanente, a partir do bronquíolo terminal". ${ }^{3}$ Após quase três décadas, em 1985, uma nova comissão redefiniu o enfisema, ampliando os conceitos já estabelecidos do Simpósio da Ciba, com a inclusão de "destruição da parede alveolar sem evidência óbvia de fibrose", e integrando o conceito de bronquite crônica e enfisema na DPOC. ${ }^{4}$ Estas duas "entidades" apresentavam a obstrução das vias respiratórias como característica comum e obrigatória. A normalização dos fluxos expiratórios nos testes de função respiratória, de forma espontânea ou após o uso de broncodilatadores, definiu fisiopatologicamente a reversibilidade, que é um dos grandes divisores da diferenciação da DPOC e da asma. Em 1998, uma equipe internacional produziu um documento que está se impondo como norteador da estratégia global para o diagnóstico, conduta e prevenção da DPOC (exatamente nesta ordem), o chamado GOLD (Global Iniatitive for Chronic Obstructive Lung Disease) ${ }_{,}^{4}$ sendo a sua definição literal: "limitação geralmente progressiva do fluxo das vias aéreas inferiores, associada à resposta inflamatória anormal do pulmão a substâncias anóxicas ou a gases, particularmente à fumaça do cigarro". Neste documento, houve uma profunda mudança de conceitos da DPOC: a aceitação da inflamação como indutora e constituinte da DPOC; a abolição das definições de bronquítico crônico e enfisema; e a aceitação do tabagismo como causador da doença.

A desvalorização da importância dos conceitos de bronquite crônica e de enfisema, apesar das diferenças do comportamento clínico, terapêutico e prognóstico, facilita a compreensão da 
etiopatogenia da DPOC.

O diagnóstico de DPOC no grupo de tabagistas ainda é baixo, cerca de 15\%. Esta dificuldade se deve à baixa sensibilidade da espirometria para o diagnóstico precoce. ${ }^{5} \mathrm{O}$ aumento do volume residual e as alterações nas tomografias computadorizadas de tórax ainda não foram incorporados como critérios de diagnóstico de DPOC.

A DPOC adquiriu um status de epidemia, mas o conhecimento dos seus mecanismos inflamatórios ainda está na fase inicial e os métodos atuais de diagnóstico continuam sendo os mesmos de décadas atrás. Ou seja, a perspectiva do aumento do número de doentes ainda permanece elevada.

\section{Inflamação na DPOC}

A inflamação encontrada nos enfisemas centroacinares foi descrita inicialmente nos trabalhos realizados em 1956, por Mc Lean, ${ }^{6} \mathrm{e}$ em 1957, por Leopold e Goug. ${ }^{7}$ Naquela época, houve dificuldade de se aceitar a relação da inflamação com o enfisema. Em ambos os trabalhos, as amostras analisadas vinham de necropsias que podiam estar contaminadas por bactérias após a morte dos pacientes e mimetizar padrões de "broncopneumonia distal". Associada a este fato, a visão da época sobre os mecanismos e respostas inflamatórias no pulmão era de que, isoladamente ou em conjunto, os processos patogênicos podiam curar sem cicatrizes, curar com cicatrizes (fibrose) e apresentar inflamação persistente, com distribuição heterogênea e de intensidade variável.

Em algumas circunstâncias, como a infecção e o fumo, os leucócitos e os macrófagos migram em grande quantidade para o pulmão. Lá são ativados e geram uma reação inflamatória que ao longo dos anos apresenta consequências na estrutura e na funcionalidade pulmonar. Este processo inflamatório acontece nas pequenas vias respiratórias (menores que $2 \mathrm{~mm}$ ), sendo normalmente tênue e contínuo. Postula-se que a responsável pela ruptura das estruturas epiteliais de sustentação alveolar seja a inflamação persis- tente das vias respiratórias distais em pacientes com DPOC. Assim, os alvéolos e ductos alveolares coalescem de forma irregular e definitiva. ${ }^{8}$

As células inflamatórias recrutadas na DPOC liberam substâncias como a elastase, as colagenases e os produtos oxidantes, que superpostos aos oxidantes inalados da fumaça do cigarro, atuam modificando os componentes da matriz extracelular. Assim, o pulmão adquire um novo modelo, deformado (estiramento e desaparecimento dos tabiques alveolares formando espaços aéreos maiores e compressões brônquicas associadas a áreas de hiperinsuflação), irreversível e que leva ao prejuízo de uma das mais primitivas funções da vida, o próprio ato respiratório. ${ }^{9}$

\section{Patogenia}

O mecanismo inflamatório da DPOC envolve diferentes células, interleucinas (IL) e produtos oxidantes, que formam um caldo inflamatório e que se relacionam com a matriz extracelular, modificando o arranjo da estrutura pulmonar e os seus componentes como as fibras elásticas e o músculo bronquiolar (figura 1).

As fibras elásticas foram estudadas por vários patologistas e anatomistas até a década de 70 do século XX. Seus achados estabeleceram que o pulmão é um "órgão elástico". Este fundamento talvez tenha sido a semente do conhecimento fisiopatológico, já que as mudanças funcionais encontradas na DPOC demonstram a perda progressiva da capacidade elástica do pulmão. ${ }^{10}$

Na DPOC, a participação dos músculos das vias respiratórias na patogenia é pouco valorizada. Se eles atrofiam, hipoplasiam, hipertrofiam, hiperplasiam ou ficam disfuncionais são questões que devem ser investigadas. Talvez o que tenha contribuído para a existência dessas dúvidas seja o achado funcional (espirométrico) de pouca ou nenhuma resposta de relaxamento brônquico na utilização dos broncodilatadores. ${ }^{10}$

Em estudos histopatológicos com pacientes com DPOC utilizando métodos imuno-histoquímicos, o linfócito T CD8+ encontrava-se 
Figura 1: Escarro induzido (EI) neutrofílico de paciente com DPOC.

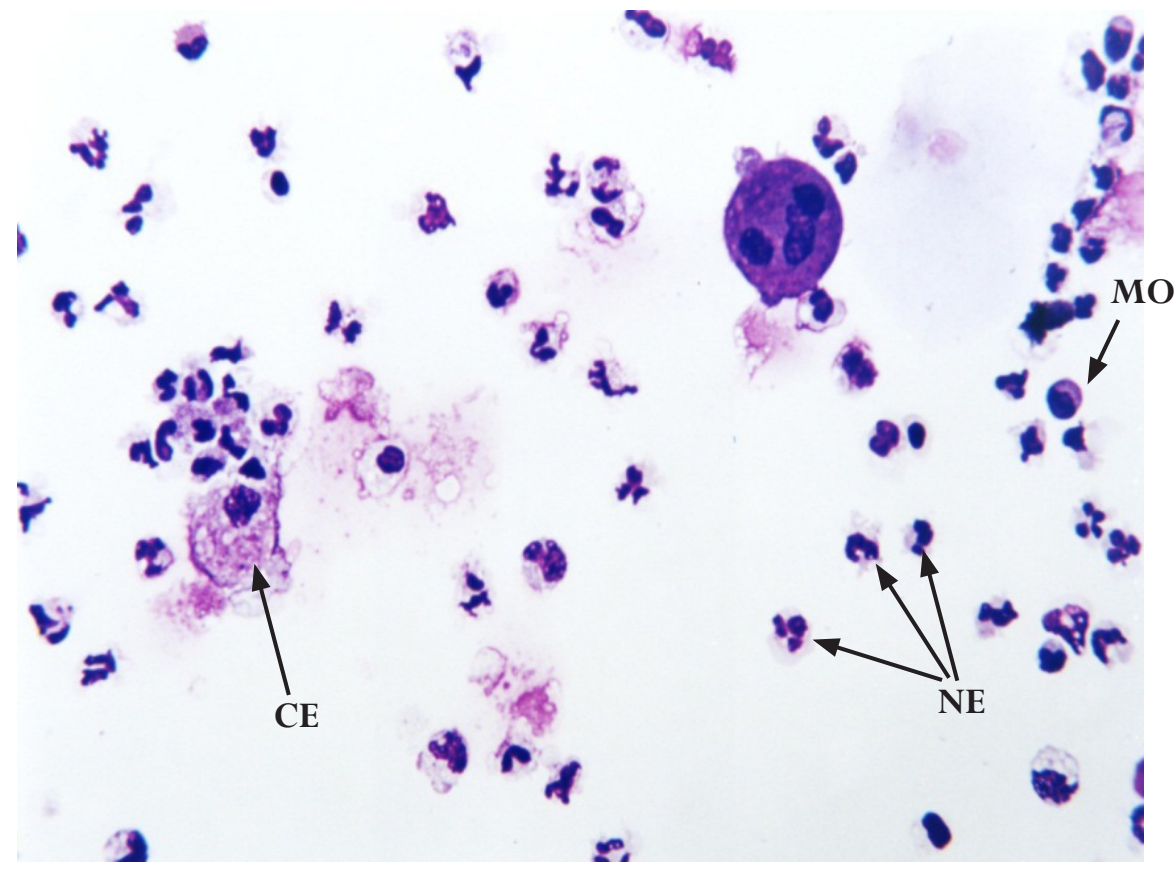

Paciente com DPOC, sem exacerbação infecciosa, com predomínio no material de EI por células neutrofílicas. Não há visualização de bactérias intracitoplasmática ou no meio extracelular (HE - grande aumento $-400 \mathrm{X})$. O macrófago e os neutrófilos são as principais células encontradas nos pacientes com DPOC. Legenda: $\mathrm{NE}=$ neutrófilos; $\mathrm{CE}=$ células escamosas; $\mathrm{MO}=$ monócito.

em quantidade significativamente superior aos dos grupos-controle. A participação linfocitária na DPOC foi o principal e mais recente avanço da sua patogenia (figura 2 ). ${ }^{11}$

Contudo, não é ético estudar a análise estrutural da DPOC através de biópsias seriadas em um mesmo paciente. Logo, outros métodos científicos devem ser desenvolvidos para prosseguir neste conhecimento fisiopatológico.

O escarro induzido (EI), inicialmente utilizado como método para o diagnóstico microbiológico, foi metodologicamente reestudado e aceito como um instrumento de investigação da asma na década de 90 do século XX. Na DPOC, que é uma doença inflamatória das vias respiratórias inferiores, o EI ainda está sendo agregado como um método para o conhecimento da sua patogenia. ${ }^{12,13}$

A literatura médica ainda é escassa sobre as modificações das fibras elásticas e do músculo brônquico e sobre como e qual é a participação do linfócito T CD8+ na fisiopatogenia da DPOC.

\section{Teorias fisiopatogênicas da DPOC}

\section{Teoria holandesa}

A hiper-reatividade brônquica (HRB) não específica representa a capacidade anormal de diminuição do calibre brônquico a estímulos inalados, e é um dos mecanismos fisiopatológicos de diminuição do fluxo aéreo respiratório existente em algumas doenças obstrutivas, especialmente na asma. ${ }^{14}$

Orie e cols. ${ }^{15}$ em 1961, demonstraram que a HRB se correlacionava com o maior declínio do volume expiratório forçado $\left(\mathrm{VEF}_{1}\right)$ nos fumantes. A partir desta constatação, considera-se que uma parcela de pacientes tabagistas poderia ter como gênese do desenvolvimento da DPOC a HRB. Tal proposta ficou conhecida como a teoria holandesa. ${ }^{16}$

Estudos com pacientes com DPOC tabagistas e asmáticos, utilizando métodos de broncoprovocação com metacolina ou histamina, demonstraram que em alguns tabagistas 
Figura 2: Marcação das células CD8+ pela técnica da imuno-histoquímica em paciente DPOC.

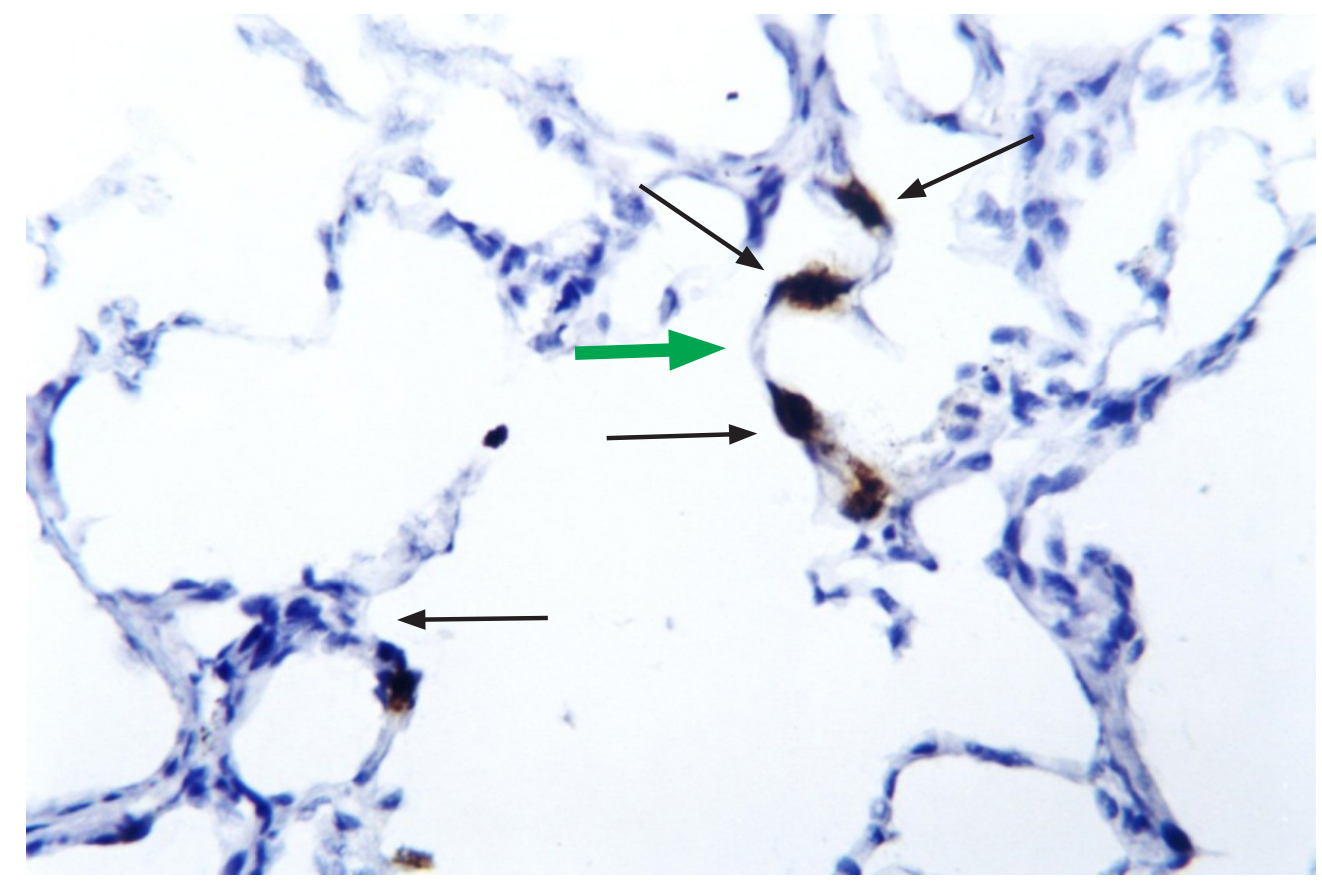

Paciente enfisematoso com material de tecido pulmonar com marcação por mieloperoxidase para células CD8+ (setas pretas). Note a tendência a agrupamentos. Área de atrofia septal (seta verde) com as células ocupando todo o septo (grande aumento-400X).

a HRB aferida apresentava valores semelhantes aos dos asmáticos. Outra constatação foi que a HRB nos fumantes diminuía após a cessação do tabagismo. Logo, o fumo foi considerado como fator estimulante para a broncoconstricção. ${ }^{17}$

Taskin e cols., em 1996, demonstraram que o fenômeno da HRB existia nos pacientes com bronquite crônica e enfisema pulmonar e que não havia diferenças estatísticas da intensidade e da frequência da HRB entre os grupos, ${ }^{17}$ contrariando a postulação de que este fenômeno era exclusivo aos bronquíticos crônicos.

A participação da HRB como um dos mecanismos de obstrução na DPOC está sendo revista. As observações de que fumantes não asmáticos podem apresentar maior sensibilização para certos alérgenos ocupacionais, assim como possuir valores de IgE e de eosinófilos sanguíneos maiores do que nas pessoas não tabagistas e sem antecedentes alérgicos, contribuíram para a revitalização da teoria holandesa. ${ }^{18}$

Teoria elastase-antielastase

As enzimas proteolíticas são encontradas nos grânulos secretados de neutrófilos e macrófagos alveolares e atuam através de digestão de micro-organismos, de restos celulares e de produtos da coagulação para a proteção pulmonar. A sua atividade proteolítica é também exercida sobre as proteínas estruturais do pulmão.

Em algumas circunstâncias, como na infecção ou no fumo, os neutrófilos migram em grande quantidade para o pulmão. Durante este processo, as células neutrofílicas podem liberar suas enzimas com a finalidade de preservação pulmonar. Assim, elas são liberadas em grande quantidade e indiscriminadamente, reconhecem os seus sítios de interação enzimática, mas não têm a capacidade de distinguir se são substâncias agressoras ou substâncias nativas. Isto é, elas atuariam sobre as proteínas dos microorganismos e sobre as proteínas que compõe a estrutura pulmonar.

A elastase lisossomal neutrofílica é a principal enzima que age degradando a elastina, componente da estrutura das fibras elásticas. Em condições normais, a atividade enzimática proteolítica é prevenida pelas enzimas antiproteolíticas. 
As antiproteases são provenientes do sangue, tecidos e secreções brônquicas, sendo a mais destacada para a DPOC a alfa-1 antiprotease.

Laurell e Erickson, ${ }^{19}$ em 1963, conseguiram correlacionar a deficiência de uma proteína inibidora, a alfa- 1 antiprotease, com o enfisema pulmonar. Com este resultado, naturalmente concluiu-se que a DPOC era decorrente do desequilíbrio de substâncias proteolíticas e antiproteolíticas no pulmão. Em outras palavras, ou as proteases estariam em excesso ou as antiproteases estariam diminuídas. Alguns modelos experimentais de DPOC foram desenvolvidos a partir desta teoria. Contudo, ela não se adapta a todos os pacientes com DPOC, pois poucos - menos de 1\% - apresentam deficiência de alfa-1 antiprotease. Portanto, a quase totalidade dos pacientes possui valores sanguíneos da antiprotease dentro da faixa da normalidade. Outro empecilho para a aceitação universal da teoria elastase-antielastase seria que a maioria dos fumantes não desenvolve a DPOC, apesar da migração e ativação de neutrófilos nas vias respiratórias dos tabagistas.

A teoria elastase-antielastase permite justificar o enfisema do tipo panacinar, que é o que ocorre preferencialmente nos pacientes com deficiência de alfa-1 antiprotease.

\section{Teoria oxidante-antioxidante}

A fumaça do cigarro resulta da combustão do tabaco, que pode ser completa na porção distal (incandescente) dos cigarros, onde alcança temperaturas de até $850^{\circ} \mathrm{C}$, e incompleta na medida em que se distancia desta zona. Os produtos dessa combustão sofrem oxidação pelos mecanismos de pirólise (decomposição térmica com formação de pequenas moléculas orgânicas), de pirossíntese (novas substâncias oriundas da recombinação das moléculas fracionadas), além da destilação de alguns componentes do tabaco (nicotina, por exemplo). A combinação destes três mecanismos leva à formação de um combinado heterogêneo, com duas fases: a particulada (condensada) e a gasosa.
Mais de 4.000 substâncias podem ser geradas pelo ato de fumar. O número de substâncias e sua concentração na fumaça do cigarro dependem das variações climáticas e dos constituintes da região onde foi plantado o tabaco, do modo de cultivo, preparo e fermentação. As substâncias mais estudadas no condensado são a nicotina, os fenóis, os cresóis, os hidrocarbonetos aromáticos policíclicos (benzopireno, dibenzoantraceno, dibenzofluoranteno, benzofenantreno, criseno, indenopireno), os ácidos orgânicos, as cetonas, os álcoois e os polióis. Na fase gasosa, encontra-se o nitrogênio, o oxigênio, o dióxido de carbono, o monóxido de carbono, o hidrogênio, o argônio, o metano, os hidrocarbonetos saturados e não saturados, as carbonilas, o ácido cianídrico, o vapor d’água, o óxido de nitrogênio, o dióxido de nitrogênio, a amônia, o formaldeído, o acetaldeído, acroleína, o propioaldeído, o isovaliraldeído, a metilacetona, a butanona, o furfural, o dimetil e metilfuran, o ácido acético, a acetonitrila, o benzeno, o tolueno, o xileno, o cloreto de metila, os derivados carbonilas e os vários ácidos orgânicos.

O trato respiratório é constantemente exposto aos efeitos da oxidação. As moléculas de oxigênio, ozônio, dióxido de nitrogênio, dióxido de enxofre e a fumaça do cigarro têm forte efeito oxidativo. Durante infecções respiratórias, os oxidantes também podem ser formados pelos granulócitos e macrófagos. Estas células têm produtos oxidantes para destruir os micro-organismos que penetram no corpo pelas vias respiratórias. Apesar disso, no curso deste processo, a atividade oxidativa também causa lesão nos tecidos circundantes. Felizmente, o trato respiratório é equipado com um sistema antioxidante que impede estes efeitos. Várias substâncias como vitamina C, glutationa, ácido úrico, bilirrubina, vitamina $\mathrm{E}$, vitamina $\mathrm{A}$ e albumina possuem a capacidade de bloquear a ação de moléculas oxidativas.

Os agentes oxidantes podem aumentar a quantidade de muco secretado pelas glândulas brônquicas, aumentar a migração de neutrófilos para o pulmão, inativar antiproteases e proliferar fibroblastos. ${ }^{20}$ 
A alteração no equilíbrio de oxidante e antioxidante está sendo relatada em várias doenças pulmonares, como a síndrome de angústia respiratória aguda, asma, fibrose pulmonar idiopática e a DPOC. Este desequilíbrio é principalmente descrito no pulmão, por causa da pronta e direta exposição a substâncias oxidativas da fumaça do cigarro e da poluição atmosférica, causando estresse oxidativo.

Teoria do desequilíbrio das subpopulações linfocitárias (CD4 e CD8)

Amadori e cols., ${ }^{21}$ em 1995, determinaram que $5 \%$ da população de doadores saudáveis apresentavam no sangue periférico o valor da relação CD4/CD8 menor que 1. Sabendo-se que a DPOC somente acontece uma parcela de fumantes (aproximadamente 15\%), sinalizaram que a menor relação CD4/CD8 identificava os possíveis doentes. Ou seja, tabagistas com diminuição prévia da relação CD4/CD8 no sangue periférico seriam as pessoas que desenvolveriam a DPOC. Isto é ainda uma postulação patogênica.

\section{Teoria da infecção viral latente}

Keicho e cols., ${ }^{22}$ em 1997, propuseram a participação viral na patogenia da DPOC. A presença do adenovírus nas células epiteliais das vias respiratórias inferiores em doentes com DPOC foi encontrada em pacientes no período intercrise, sem exacerbações. A hipótese proposta foi que em pacientes com DPOC a presença da infecção viral latente representava mais um estimulador da inflamação, além do tabagismo e das exacerbações infecciosas, levando à liberação de maiores quantidades de mediadores inflamatórios, como o ICAM-1 e a IL8, e ampliando o processo inflamatório já instalado pelo tabagismo. Tais defensores da participação viral no desenvolvimento e agravamento da DPOC demonstraram que o vírus sincicial respiratório também pode ser encontrado em alguns doentes. Assim, pode-se ter infecção viral latente em alguns pacientes com DPOC, o que influenciaria no fluxo e na intensidade da inflamação nas vias respiratórias inferiores.

\section{Teoria inflamatória-imunitária}

Nos idos de 1990, vários grupos de estudo patogênico de DPOC no mundo começaram a associar as teorias de desequilíbrio de substâncias liberadas pelos neutrófilos e macrófagos, tais quais as proteases e os oxidantes, como pertencentes a um único processo de desenvolvimento fisiopatológico da doença. Assim, as teorias elastase-antielastase e oxidante-antioxidante começaram a ser interpretadas conjuntamente. Suas informações foram reunidas, constituindo uma proposta de modelo inflamatório da DPOC, contendo predominantemente informações da participação de macrófagos e neutrófilos. ${ }^{23}$

Nesta mesma década, outros estudos com amostras de biópsia pulmonar demonstraram que os linfócitos T CD8+ estavam significativamente aumentados nas vias respiratórias inferiores dos pacientes com DPOC. Este fato modificou o pensamento inflamatório da DPOC. Assim, o modelo inflamatório da DPOC composto por neutrófilos e macrófagos apresentava novo ator celular, o linfócito T CD8+.

O estudo histopatológico de Saetta e cols. ${ }^{24}$ demonstrou que o processo inflamatório na DPOC ocorre nas pequenas vias aéreas (bronquíolos menores que $2 \mathrm{~mm}$ ) e no parênquima pulmonar. Os bronquíolos eram obstruídos pela fibrose e pela infiltração de macrófagos e de linfócitos $\mathrm{T}$. O parênquima pulmonar apresentou-se distorcido e com aumento do número de macrófagos e linfócitos T, predominantemente de linfócitos CD8+.

A função das células T CD8+ na DPOC ainda é parcialmente conhecida, mas algumas hipóteses foram levantadas:

1. participam na apoptose e na destruição de células epiteliais da parede alveolar, através da liberação de perforinas e TNF- $\alpha$;

2. atuam na defesa de infecção viral latente;

3. regulam a resposta imunitária pela tole- 
rância a antígenos depositários nos órgãos;

4. estimulam a proliferação de fibras colágenas, verificadas pelo very late antigen (VLA-1).

A hipótese inicial da presença dos linfócitos T CD8 nos pacientes com DPOC foi na defesa das infecções virais repetidas, por causa dos conhecimentos prévios da sua capacidade como célula citotóxica. Elas atuariam destruindo as partículas virais e as células que sofreram modificações pela atuação dos vírus. Todavia, esta é ainda uma das hipóteses para a persistência do linfócito T CD8 na via respiratória.

O desenvolvimento da teoria inflamatóriaimunitária está auxiliando o avanço na compreensão da patogenia da DPOC. Esta teoria é um avanço no conhecimento inflamatório multicelular da DPOC e apresenta novos caminhos de investigação da doença, inclusive com a participação da imunidade celular.

\section{Hipótese para o desenvolvimento da hiperinsuflação}

Letulle, ${ }^{25}$ em 1924, citava que os tabiques alveolares se adelgaçam e o seu tecido funda- mental se hipotrofia e/ou atrofia. Este processo seria de "distrofia parenquimatosa" e poderia ser progressivo. Entretanto, o que já se sabe é que as estruturas de sustentação alveolar são fundamentais na configuração espacial dos tabiques alveolares. Se alteradas, os alvéolos perdem a sua sustentação e começam a se romper. Este processo transformaria várias unidades de alvéolos em uma única unidade alveolar, modificando a proporcionalidade da relação entre alvéolos e capilares, contribuindo para a o desequilíbrio da ventilação e da perfusão. Esse aumento dos espaços aéreos na DPOC tem como característica a progressão e a irreversibilidade.

\section{Fisiopatologia da DPOC}

Quando uma pessoa inspira profundamente logo após uma expiração forçada, o volume de ar no pulmão pode aumentar até quatro vezes. Se a expansão pulmonar fosse uniforme seria necessário um aumento linear das dimensões pulmonares em quase duas vezes. Contudo, as diferenças regionais do sistema respiratório dificultam esse resultado matemático. Em parte, isto é explicado pela forma piramidal dos pul-

Figura 3: Fibras elásticas no pulmão enfisematoso.

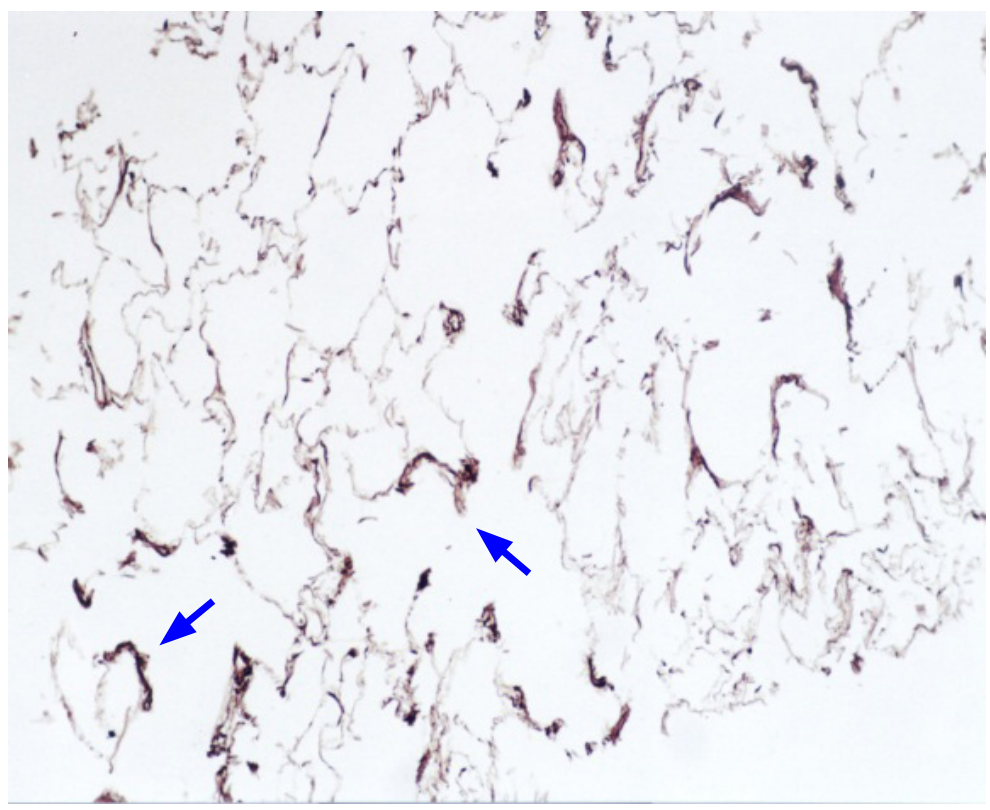

Corte panorâmico de pulmão enfisematoso mostrando proeminências de fibras elásticas (setas) ao nível de ductos alveolares/bronquíolos respiratórios. Notem o acúmulo desigual na distribuição das fibras elásticas (técnica de resorcina-fucsina de Weigert-médio aumento-100X) 
mões e pela pressão gravitacional. As maiores expansões ocorrem nos ductos alveolares e nos alvéolos, que mantêm os ângulos das divisões brônquicas estáveis. Isto é denominado de expansão isotrópica.

A estrutura pulmonar é constituída de fibras elásticas e colágenas. Os dois tipos de fibras estão em aposição, formando um modelo estrutural semelhante a um andaime, com fibras relativamente mais ou menos distensíveis, que se movem respeitando umas às outras (figura 3).

Durante a inspiração, a partir do volume residual (VR), as fibras se desenovelam dos ductos alveolares expandindo longitudinalmente e ampliando o lúmen alveolar. Há o aumento das forças nos septos alveolares, diminuindo as irregularidades das suas paredes, abrindo as dobras dos septos e cooptando alvéolos que possam estar colapsados. Este mecanismo aumenta a superfície alveolar, facilitando a passagem de gás pela membrana alvéolocapilar. Este fenômeno é acompanhado do estreitamento e alongamento dos capilares alveolares, que se situam nas partes centrais dos septos alveolares. Assim, harmonicamente os capilares se afinam na insuflação, diminuindo o volume sanguíneo que entra em contato com os alvéolos, facilitando a troca gasosa.

Quatro itens são conhecidos para a manutenção da luz das vias aéreas durante a expiração máxima: cartilagem, fibras elásticas, fibras colágenas e tensão superficial (TS).

No pulmão, os espaços aéreos não são uniformes e o sentido preferencial do fluxo aéreo dependerá das resistências encontradas na inspiração e na expiração.

A distribuição dos gases é influenciada pela força gravitacional, contratilidade da musculatura lisa do brônquio e alterações da parede brônquica. O colapso prematuro do pulmão eleva o VR, sendo causas comuns para este aumento: a diminuição da elasticidade pulmonar (idade e DPOC), o aumento da resposta muscular brônquica (asma) e a maior espessura da parede brônquica (asma, bronquiectasias e DPOC).

Nas bifurcações brônquicas, a abertura de um brônquio pode acontecer antes de outro. Há, também, a formação de pequenas bolhas de líquido que se moveriam para cima e para baixo das vias respiratórias, levando à obstrução variável do fluxo de ar.

O modelo dinâmico de fechamento das vias aéreas de Mead e cols. ${ }^{4}$ proposto em 1967, denominado de teoria do ponto de igual pressão, é o mais aceito para obstrução do fluxo expiratório. A pressão nos alvéolos é atmosférica ao término da inspiração e subatmosférica durante a expiração. Ela diminui progressivamente ao longo das vias aéreas, até num determinado ponto da via respiratória, na qual não haveria mais fluxo aéreo. O fluxo cessaria sem o colapso total do sistema broncoalveolar. Neste ponto, considera-se que haja o equilíbrio das pressões intraluminal e extraluminal. Nos pacientes com alterações dos componentes elástico e de colágeno e com espessamento da parede brônquica (com DPOC, por exemplo), este ponto de igual pressão pode se localizar mais distalmente.

As alterações funcionais do enfisema estão relacionadas à diminuição tanto da área pulmonar para a realização da troca gasosa, como da pressão de recolhimento.

A divisão das vias respiratórias que acontece na fase de desenvolvimento é determinante do desenho e das dimensões dos pulmões maduros.

As vias aéreas podem ser compreendidas como de grandes e pequenas vias. As pequenas vias aéreas compõem-se de bronquíolos terminais, bronquíolos transicionais e bronquíolos respiratórios. Os brônquios se dicotomizam em ramos menores, que podem ter extensão e diâmetros diferentes. $\mathrm{O}$ ácino é definido como o complexo de alvéolos conectado aos bronquíolos. O diâmetro interno dos ácinos das vias respiratórias (ducto sem alvéolo) diminui progressivamente de 500 até $300 \mu \mathrm{m}$.

No modelo de dicotomia simétrica de brônquios são encontradas 23 gerações brônquicas. A área seccional transversa dos brônquios aumenta conforme a divisão das vias aéreas.

Nas grandes vias aéreas, os músculos lisos estão preferencialmente circundando o brôn- 
quio, mas a cartilagem aí situada diminui os efeitos da contração muscular. Dos brônquios lobares aos bronquíolos, os músculos são dispostos em forma de hélice, às vezes longitudinalmente, o que também limita o estreitamento excessivo da luz.

\section{Nas pequenas vias respiratórias}

Niewoehner e cols., ${ }^{26}$ em 1974, e Cosio e cols. ${ }^{27} \mathrm{em} 1980$, demonstraram que as alterações morfológicas nas pequenas vias respiratórias na DPOC apresentavam correlações com a função pulmonar. Isto é, a oclusão da luz bronquiolar, a metaplasia de células caliciformes, a metaplasia escamosa, a presença de úlceras na mucosa brônquica, a hipertrofia/hiperplasia do músculo liso, o infiltrado celular inflamatório, a fibrose intersticial e peribronquiolar e o depósito de pigmentos na parede das vias respiratórias estariam diretamente relacionados à obstrução brônquica. As primeiras anormalidades encontradas nestes trabalhos foram as alterações do epitélio (metaplasia escamosa) e o infiltrado inflamatório crônico, com aumento discreto do tecido conjuntivo da parede das pequenas vias respiratórias. Com a progressão da doença, eles verificaram que o infiltrado inflamatório celular pouco se modificava, mas havia um aumento progressivo na quantidade de pigmentação do tecido conjuntivo.

\section{Enfisema centrolobular (centroacinar) e panlobular (panacinar)}

Em estudos histopatológicos, a destruição da parede alveolar precede as alterações de alargamento dos espaços alveolares, sendo que estas se correlacionam com a alteração da pressão de recolhimento pulmonar.

A destruição pulmonar que ocorre preferencialmente no centro do lóbulo é denominada de centrolobular, mas se distribuída em todo o lóbulo é conhecida como panlobular.

Eildeman e cols., ${ }^{28}$ em 1989, demonstraram que a DPOC sem deficiência de alfa-1 antitripsina pode apresentar os dois modelos de destruição parenquimatosa simultanemente.

Kim e cols., ${ }^{29}$ em 1991, demonstraram, em 34 pacientes com DPOC submetidos a ressecções pulmonares, que os enfisemas panlobular e centrolobular apresentavam alterações distintas e significativas na mecânica pulmonar. No enfisema panlobular havia infiltração parenquimatosa, destruição difusa do lóbulo e perda do recolhimento pulmonar. No enfisema centrolobular havia infiltração bronquiolar e peribronquiolar, espessamento, destruição e diminuição da luz bronquiolar, ocasionando aumento da resistência das vias aéreas e diminuição da pressão de recolhimento pulmonar. Estes achados demonstraram que as propriedades mecânicas são diferentes nesses dois subtipos de enfisema desde o início da doença, acentuando-se com o aumento progressivo do espaço aéreo.

$\mathrm{O}$ enfisema centrolobular possui aumento significativo da quantidade de músculo liso e de fibrose nas pequenas vias respiratórias em relação ao enfisema panlobular. Além disso, a quantidade de vias respiratórias menores que $400 \mu \mathrm{m}$ é maior no enfisema centrolobular $\mathrm{e}$ isto se correlaciona com o aumento da resistência do fluxo aéreo nas pequenas vias, o que não acontece no enfisema panlobular. Estes achados da patologia do enfisema centrolobular mostram que a obstrução do fluxo é em decorrência principalmente das anormalidades das vias respiratórias, sendo que a diminuição da pressão de recolhimento se caracteriza mais como um fator adicional do que primordial na obstrução do fluxo. Ao contrário, o enfisema panlobular, a obstrução do fluxo aéreo é uma função da redução da pressão de recolhimento.

Anderson e Foraker, ${ }^{30}$ em 1973, consideraram que a DPOC apresentava vias patogênicas diferentes. Postularam que a agressão ao pulmão nos enfisemas panlobulares seria através de substâncias provenientes da corrente sanguínea, pensamento justificado pelo caráter de distribuição difusa e homogênea deste enfisema. Mas, nos enfisemas centrolobulares que apresentam a doença no centro do ácino, a via respiratória seria a responsável pela distribuição de substâncias nocivas ao pulmão. 
Lesão do epitélio das vias respiratórias inferiores

A barreira de proteção do epitélio das vias respiratórias é quebrada pelo cigarro. O epitélio torna-se desnudo, com úlceras na sua mucosa, transformação metaplásica em células escamosas e células caliciformes.

Muitos trabalhos demonstram que o fumo modifica a permeabilidade epitelial a substâncias eletron-densas, aumentando o conteúdo de exsudato plasmático nas vias respiratórias e ampliando o recrutamento das células inflamatórias (neutrófilos, macrófagos, eosinófilos).

O epitélio respiratório está alterado na DPOC em todas as fases de estadiamento. A sua reparação não é conseguida plenamente, apesar da cessação do tabagismo e do uso de medicamentos anti-inflamatórios como o corticosteroide.

\section{Reparo das vias respiratórias inferiores}

A lesão alveolar desencadeada pela elastase neutrofílica inicia resposta de reparo com a expressão do gene da elastina. No entanto, a integridade tecidual não é recuperada.

O fumo altera a capacidade de regeneração do epitélio das vias respiratórias. Os fibroblastos e os fatores liberados pelas células epiteliais (TGF $\beta$, fibronectina) podem modular a proliferação das próprias células epitelias e estão em maiores concentrações nos pacientes com DPOC.

\section{Conclusão}

A ideia de que o enfisema resulta da injúria proteolítica dos septos alveolares tem se mantido como a teoria que mais se adapta aos conhecimentos adquiridos nestes últimos anos. Na hipótese proteinase-antiprotease ocorre uma liberação episódica ou regular de proteinases no tecido pulmonar capaz de digerir as proteínas de sustentação da estrutura pulmonar. Normalmente, o pulmão é protegido pela ação de inibidores de proteases, principalmente provenientes do sangue, mas que também podem ser produzidos localmente. $\mathrm{O}$ enfisema resultaria num desbalanço da relação protease-antiprotease favorecendo as proteases. $\mathrm{O}$ reparo pulmonar seria feito de forma insuficiente e deficiente e logo mudanças funcionais poderiam ser verificadas. É evidente que os fatores de risco já identificados seriam o principal determinante do início do processo inflamatório celular e do estresse oxidativo. Quando associados a uma predisposição genética, levariam a uma disfunção das células inflamatórias, como os linfócitos T CD8+ e os macrófagos, que se manteriam ativados no tecido pulmonar, acarretando progressiva destruição parenquimatosa e tendo como consequência final a DPOC.

\section{Referências}

1. Laennec RTH. Laennec RTH. In: A treatise on diseases of the chest and on mediate auscultation. 4th ed. London Translate by Forbes: Logmans; 1834.

2. Wright RR. Bronchial atrophy and collapse in chronic obstructive pulmonary emphysema. Am J Pathol. 1960;37(1);63-71.

3. Ciba Fundations Guest Symposium. Terminology, definitions, and classification of chronic pulmonary emphysema and related conditions. Thorax. 1959;14:286-99.

4. Global initiative for chronic obstructive lung disease. [Homepage on internet]. [Updated 2011 December. Cited 2012 Jul 09]. Available from: http://www.goldcopd.org/guidelinesglobal-strategy-for-diagnosis-management. html.

5. Barnes PJ. Chronic Obstructive Pulmonary Disease. N Engl J Med. 2000;343(4):269-80.

6. Mc Lean KH. Microscopic anatomy of pulmonary emphysema. Aust Ann Intern Med. 1956; 5:73-88.

7. Leopold JG, Gough J. Centrilobular form of hypertrophic emphysema and its relation to chronic bronchitis. Thorax. 1957;12:219-35.

8. Cosio MG, Ghezzo H, Hogg JC, Corbin R, Loveland M, Dosman J, Macklem PT. The relations between structural changes in small airways and pulmonary functions tests. N Engl J Med. 1977;298:1277-81.

9. Hogg JC, Senior RM. Chronic obstructive pulmonary disease c2: pathology and biochemistry of emphysema. Thorax. 2002;57(9):830-4.

10. Wright RR. Elastic tissue of normal and emphysematous lungs. A tridimensional 
histologic study. Am J Pathol. 1961;39:355-63.

11. Hogg JC, Chu F, Utokaparch S, Woods R, Elliot WM, Buzatu L, et al. The nature of small-airway obstruction in chronic obstructive pulmonary disease. N Engl J Med. 2004;350(26):2645-53.

12. Costa CH, Rufino R, Lapa e Silva JR. Inflammatory cells and their mediators in COPD pathogenesis. Rev Assoc Med Bras. 2009;55(3):347-54.

13. Costa C, Rufino R, Traves SL, Lapa e Silva JR, Barnes PJ, Donnelly LE. CXCR3 and CCR5 chemokines in induced sputum from patients with COPD. Chest. 2008;133(1):26-33.

14. Yan K, Salome CM, Woolcock AJ. Prevalence and nature of bronchial hyperresponsiveness in subjects with chronic obstructive pulmonary disease. Am Rev Respir Dis. 1985;132:25-9.

15. Orie NG, Sluiger HJ, De Vries K, et al. The host factor in bronchilitis. In Orie NGM, Sluiter HJ, editors: Bronchitis, An International Symposium. Netherlands: Assen; 1961.p. 43-59.

16. O'Connor GT, Sparrow P, Weiss ST. The role of allergy and nonspecific airway hyperresponsiveness in the pathogenesis of chronic obstructive pulmonary disease. Am Rev Respir Dis. 1989;140(6):225-32.

17. Taskin DP, Altose, Connett JE. Methacoline reactivity predictis changes in lung function over time in smokers with early chronic obstructive pulmonary disease. Am J Respir Crit Care Med. 1996;153:1802-11.

18. Postma DS, De Vries K, Köeter GH, Sluiter HJ. Independent influence of reversibility of airflow obstruction and nonspecific hyperreactivity on the long-term course of lung function in chronic airflow obstruction. Am Rev Respir Dis. 1986;134(2):276-80.

19. Laurell CB, Eriksson S. The electrophoretic $\alpha$-globulin pattern of serum $\alpha$-antitrypsin deficiency. J Clin Invest. 1963;15:12-140.

20. Decramer M, Janssens W, Miravitlles M.
Chronic obstructive pulmonary disease. Lancet. 2012;379(9823):1341-51.

21. Amadori A, Zamarchi R, De Silvestro G, Forza G, Cavatton G, Antonio Danieli G, et al. Genetic control of the CD/CD8 T-cell ratio in humans. Nature Med. 1995;1(12):1279-83.

22. Keicho N, Elliott WN, Hogg J, Hayashi S. Adenovirus E1A upregulates interleukin-8 expression induced by endotoxin in pulmonary epithelial cells. Am J Physiol. 1997;272(6 Pt 1): L1046-52.

23. Hogg JC. Pathophysiology of airflow limitation in chronic obstructive pulmonary disease. Lancet. 2004;364(9435):709-21.

24. Saetta M, Mariani M, Panina-Bordignon P, Turato G, Buosanti C, Baraldo S, et al. Increased expression of the chemokine receptor CXCR3 and its ligands CXCL10 in peripheral airways of smokers with chronic obstructive pulmonary disease. Am J Respir Crit Care Med. 2002;165(10):1404-09.

25. Lettule M. La tuberculose pleuro-pulmonaire. A. Maloine \& Fils, Éditeurs:Paris; 1916.

26. Niewoehner DE, Kleinerman J, Rice D. Pathologic changes in the peripheral airways of young cigarette smokers. N Engl J Med. 1974;291(15):755-8.

27. Cosio MG, Hale KA, Niewoehner DE. Morphologic and morphometric effects of prolonged cigarette smoking on the small airways. Am Rev Respir Dis. 1980;122(2):26571.

28. Eildeman DH, Ghezzo H, Kim WD, Hyatt RE, Cosio MG. Pressure-volume curves in smokers. Comparison with alpha1-antitrypsin deficiency. Am Rev Respir Dis. 1989:139(6):1452-8.

29. Kim WD, Eidelman DH, Izquierdo JL, Ghezzo H, Saetta MP, Cosio MG. Centrilobular and panlobular emphysema in smokers. Two distinct morphologic and functional entities. Am Rev Respir Dis. 1991;144(6):1385-1389. 


\section{Autores}

\begin{abstract}
Abdiel Rolim
Programa de Residência Médica e Pós-graduação em Radiologia. Hospital Universitário Pedro Ernesto. Universidade do Estado do Rio de Janeiro. Rio de Janeiro, RJ, Brasil.
\end{abstract}

\section{Adalgisa I. M. Bromerschenckel}

Programa de Pós-graduação Stricto Sensu em Ciências Médicas. Faculdade de Ciências Médicas. Universidade do Estado do Rio de Janeiro. Rio de Janeiro, RJ, Brasil.

\section{Agnaldo José Lopes}

Disciplina de Pneumologia e Tisiologia. Departamento de Especialidades Médicas. Faculdade de Ciências Médicas. Universidade do Estado do Rio de Janeiro. Rio de Janeiro, RJ, Brasil.

\section{Ana Paula V. Soares}

Serviço de Pneumologia e Tisiologia. Policlínica Piquet Carneiro. Universidade do Estado do Rio de Janeiro. Rio de Janeiro, RJ, Brasil.

\section{Anamelia C. Faria}

Serviço de Pneumologia e Tisiologia. Hospital Universitário Pedro Ernesto. Universidade do Estado do Rio de Janeiro. Rio de Janeiro, RJ, Brasil.

\section{Domenico Capone}

Disciplina de Pneumologia e Tisiologia. Departamento de Especialidades Médicas. Faculdade de Ciências Médicas. Universidade do Estado do Rio de Janeiro. Rio de Janeiro, RJ, Brasil.

\section{Eduardo Costa F. Silva}

Serviço de Alergia e Imunologia. Departamento de Medicina Interna. Hospital Universitário Pedro Ernesto. Universidade do Estado do Rio de Janeiro. Rio de Janeiro, RJ, Brasil.

\section{Elizabeth J. C. Bessa}

Disciplina de Pneumologia e Tisiologia. Faculdade de Ciências Médicas. Universidade do Estado do Rio de Janeiro. Rio de Janeiro, RJ, Brasil.

\section{Gabriela A. C. Dias}

Serviço de Alergia e Imunologia. Departamento de Medicina Interna. Hospital Universitário Pedro Ernesto. Universidade do Estado do Rio de Janeiro. Rio de Janeiro, RJ, Brasil.

\section{Jorge Eduardo Pio}

Disciplina de Pneumologia e Tisiologia. Faculdade de Ciências Médicas. Universidade do Estado do Rio de Janeiro. Rio de Janeiro, RJ, Brasil.

\section{Kênia M. da Silva}

Programa de Pós-graduação Stricto Sensu em Ciências Médicas. Faculdade de Ciências Médicas. Universidade do Estado do Rio de Janeiro. Rio de Janeiro, RJ, Brasil.

\section{Leonardo P. Bruno}

Serviço de Pneumologia e Tisiologia. Hospital Universitário Pedro Ernesto. Universidade do Estado do Rio de Janeiro. Rio de Janeiro, RJ, Brasil.

\section{Lívia I. de O. Souza}

Faculdade de Ciências Médicas. Universidade do Estado do Rio de Janeiro. Rio de Janeiro, RJ, Brasil.

\section{Mateus Bettencourt}

Programa de Pós-graduação Stricto Sensu em Ciências Médicas. Faculdade de Ciências Médicas. Universidade do Estado do Rio de Janeiro. Rio de Janeiro, RJ, Brasil.

\section{Paulo Roberto Chauvet}

Disciplina de Pneumologia e Tisiologia. Faculdade de Ciências Médicas. Universidade do Estado do Rio de Janeiro. Rio de Janeiro, RJ, Brasil. 


\section{Rafael Capone}

Programa de Residência Médica e Pós-graduação em Radiologia. Hospital Universitário Pedro Ernesto. Universidade do Estado do Rio de Janeiro. Rio de Janeiro, RJ, Brasil.

\section{Renato Azambuja}

Serviço de Pneumologia e Tisiologia. Hospital Universitário Pedro Ernesto. Universidade do Estado do Rio de Janeiro. Rio de Janeiro, RJ, Brasil.

\section{Rogério M. Bártholo}

Programa de Pós-graduação Stricto Sensu em Ciências Médicas. Faculdade de Ciências Médicas. Universidade do Estado do Rio de Janeiro. Rio de Janeiro, RJ, Brasil.

\section{Sérgio da Cunha}

Disciplina de Tratamento Intensivo. Departamento de Clínica Médica. Faculdade de Ciências Médicas. Universidade do Estado do Rio de Janeiro. Rio de Janeiro, RJ, Brasil.

\section{Thiago P. Bártholo}

Serviço de Pneumologia e Tisiologia. Hospital Universitário Pedro Ernesto. Universidade do Estado do Rio de Janeiro. Rio de Janeiro, RJ, Brasil.

\section{Verônica S. Câmara}

Serviço de Pneumologia e Tisiologia. Policlínica Piquet Carneiro. Universidade do Estado do Rio de Janeiro. Rio de Janeiro, RJ, Brasil. 